www.jcmtjournal.com

\title{
Lung cancer biopsy dislodges tumor cells into circulating blood
}

\author{
Noriyoshi Sawabata, Tomotaka Kitamura, Yuko Nitta, Tomoyo Taketa, Takeshi Ohno, Tatsuya Fukumori, \\ Takeru Hyakutake, Takahito Nakamura
}

Division of General Thoracic Surgery, Respiratory Center, Hoshigaoka Medical Center, Hirakata, Osaka 574-8511, Japan.

Correspondence to: Dr. Noriyoshi Sawabata, Division of General Thoracic Surgery, Respiratory Center, Hoshigaoka Medical Center, 4-8-1 Hoshigaoka, Hirakata, Osaka 574-8511, Japan. E-mail: nsawabata@hotmail.com

How to cite this article: Sawabata N, Kitamura T, Nitta Y, Taketa T, Ohno T, Fukumori T, Hyakutake T, Nakamura T. Lung cancer biopsy dislodges tumor cells into circulating blood. J Cancer Metastasis Treat 2017;3:16-20.

Article history:

Received: 15-11-2016

Accepted: 12-01-2017

Published: 23-01-2017

Key words:

Lung cancer,

biopsy,

circulating tumor cells

\begin{abstract}
Aim: A "seed" of lung cancer metastasis is circulating tumor cells (CTCs), which may be dislodged from a tumor during biopsy. This possibility was assessed among patients who underwent lung tumor biopsy using flexible fiber-topic bronchoscopy (FFB). Methods: The study involved six patients with non-small cell lung cancer who underwent FFB biopsy to diagnose a lesion pathologically ( 5 males and 1 female, median age 63 years, 6 adenocarcinomas, of 4 clinical-stage IA, 1 stage IB, and 1 stage IIIA), CTCs were extracted from the peripheral vein blood at pre-FFB and at post-FFB using a size selection method. Results: No tumor cell was detected at pre- and post-FFB was in three cases (50\%); no tumor cells were detected pre-FFB while CTCs were detected at post-FFB in two cases (33.3\%); and CTCs were detected at pre-FFB with numerous CTCs detected at post-FFB in one case (17.7\%). In addition, similar tendencies were observed in each analysis of singlecell and clustered-cell categories. Conclusion: These results suggest that a FFB biopsy of lung cancer may potentially dislodge CTCs from a tumor into the circulating peripheral blood.
\end{abstract}

\section{INTRODUCTION}

There are three principal methods to diagnose a pulmonary lung cancer region pathologically. One is trans-bronchial biopsy (TBB) using flexible fibertopic bronchoscopy (FFB) and others are computed tomography (CT), guided fine needle aspiration biopsy (FNAC), and surgical resection..$^{[1]}$ Each method is effective but has some weak points.

First, FNAC has the potential to disseminate cancer cells through the needle tract. ${ }^{[2]}$ According to a study using extracted human lung lobe with cancer lesions, cancer cells were detected at a rate of $10 \%$ in the saline used to wash the pulmonary lobe surface. This rate increased to $60 \%$ after FNAC. ${ }^{[2]}$ In a clinical setting. it has been reported that the rate of relapse (pleural recurrence) was higher in an FNAC group than in a control group among surgical lung cancer cases. ${ }^{[3,4]}$ In addition, there has been a recommendation use caution in employing FNAC as a method of lung cancer diagnosis based on evidence. ${ }^{[5]}$ 
Pulmonary wedge resection is also a crucial diagnostic technique for pulmonary nodules that may indicate lung cancer. This procedure also may potentially dislodge tumor cells from the surgical margin to the body, even when a specimen of pulmonary wedge resection contents histologically malignant negative surgical margin. ${ }^{[6,7]}$ Malignant-positive results in the surgical margin have been reported to be an indicator of poor prognosis in a retrospective study. ${ }^{[8]}$ Furthermore, it has been reported that malignant surgical margins of pulmonary wedge resection for lung cancer was a negative prognostic predictor in a subset analysis included in a multicenter prospective study of limited pulmonary resection for compromised lung cancer patients. ${ }^{[9]}$

TBB is also an important method in diagnosing lung cancer. However, there have been reports demonstrating a prognostic disadvantage for biopsy using FFB. ${ }^{[10,11]}$ An observational study revealed that patients who were diagnosed with lung cancer using a trans-pleural technique had a statistically $(P=0.04)$ better 5-year survival rate than patients diagnosed using TBB. ${ }^{[10]}$ This phenomenon was also reported in a study using propensity score matched analysis. ${ }^{[11]}$ These results may mean that an intervention in a cancer lesion using TBB may dislodge cancer cells from the lesion to the circulating blood.

There are also studies revealing that manipulation during lung cancer surgery has the potential to dislodge cancer cells into the circulating blood, which is reported to be aprognostic indicator of poor outcomes. ${ }^{[12-15]}$ Above all, detecting cluster circulating tumor cell (CTC) is speculated the best a strong predictor of early recurrence. ${ }^{[13]} \mathrm{FBB}$ also manipulates the area of lung cancer during biopsy; thus, CTCs might be dislodged from the lesion to the circulating blood as the same manner as surgical manipulation. For that reason we assessed the status of CTC before and after FFB biopsy to diagnose lung cancer.

\section{METHODS}

This investigation was approved by the institutional review board of the Hoshigaoka Medical Center and all patients provided their informed consent to participate in this study.

Among 6 patients with non-small cell lung cancer (NSCLC) who underwent FFB to diagnose a lesion pathologically, CTCs were extracted from a peripheral vein at pre-FFB and at post-FFB using a size selection method [ScreenCell ${ }^{\otimes}$ Cyto (ScreenCell, Westford, MA)]: using a micro-pore film that extracts formalin- fixed tumor cells. ${ }^{[16]}$ ScreenCell ${ }^{\circledR}$ Cyto is designed for cytological studies and the filter allows a fast and regular filtration, preserving the CTC morphology and microcluster structures. Blood samples were diluted with the $(\mathrm{LC} / \mathrm{CC})$ ScreenCell ${ }^{\otimes}$ (ScreenCell, Westford, MA) dilution buffers for fixed cells. At the end of filtration, the ScreenCell ${ }^{\circledR}$ Cyto filter was released onto a standard microscopy glass slide; a $7 \mathrm{~mm}$ circular coverslip was then laid down on the filter with the appropriate mounting medium.

Peripheral blood ( $3 \mathrm{~mL}$ ) was collected into an EDTA tube pre- and post-FFB. Tumor cells in two blood samples from each patient were simultaneously extracted using the method. These extracted cells were stained using a hematoxylin and eosin method and observed with a conventional microscope. Tumor cells were classified using three categories: no tumor cells detected $(\mathrm{N})$, single cell or less than four cells $(\mathrm{S})$, and clustered cells $(\mathrm{C})$.

\section{RESULTS}

FFB-TBB was carried out under localized anesthesia using radiography to confirm that a sampling device reaches hits at a lesion. Samples for cytology and pathology were collected from a lesion. Cytological diagnosis of malignancy was achieved in only four cases, while all lesions revealed a pathological diagnosis, which is the result of manipulation that FFBTBB made while contacting a cancer lesion. There was no complication during and after FFB-TBB and all patients were discharged without event.

Patient/tumor characteristics and status of CTC in each patient are shown in Table 1. There were five males and one female with a median age of 63 years, (range 59-78 years). According to CT findings, all lesions were solid and tumor size on CT findings was a median $2.5 \mathrm{~cm}$ (range $2.1-3.5 \mathrm{~cm}$ ). Tumor invasiveness status in pathological diagnosis was "invasive" in all cases. Clinical stage was clinical -- stage IA in four cases, stage IB in one case and stage IIIA in one case. Singular or cluster CTCs were detectable as shown in Figure 1. The CTC counts at pre- and post-FFB procedures are shown in Table 1. In one case CTC was detectable before FFB. This case was stage IIIA with mediastinal lymphadenopathy. In an analysis of all cell categories, no tumor cell was detected at preFFB; at post-FFB a tumor cell was detected in three cases $(50.0 \%)$. No tumor cell was detected at pre-FFB, while CTCs were detected at post-FFB in two cases $(33.3 \%)$ and CTCs were detected at pre-FFB, while numerous CTCs were detected at post-FFB in one case $(17.7 \%)$. In analysis of singular cells, no tumor 
cell was detected at pre-FFB, while in three cases cells were detected at post-FFB (50.0\%); no tumor cell was detected at pre-FFB while some CTCs were detected at post-FFB in two cases (33.3\%) while some CTCs were detected at pre-FFB. Numerous CTCs were detected at post-FFB in one case (17.7\%). In addition, in the analysis of cluster CTC alone $(n=6)$, no tumor cells were detected at pre-FFB and at post-FFB in five cases $(63.3 \%)$, with some CTCs being detected at preFFB and many CTCs detected at post-FFB in one case $(17.7 \%)$. The alterations of CTC counts are graphically demonstrated in Figure 2.

\section{DISCUSSION}

In our assessment of CTCs at pre-FFB and at postFFB biopsy, the amount of CTC is not decreased after an FFB procedure, and in cases involving CTCs the count of CTCs increased at post-FFB. These results suggest that a tumor biopsy of a lung cancer lesion has the potential to dislodge tumor cells into

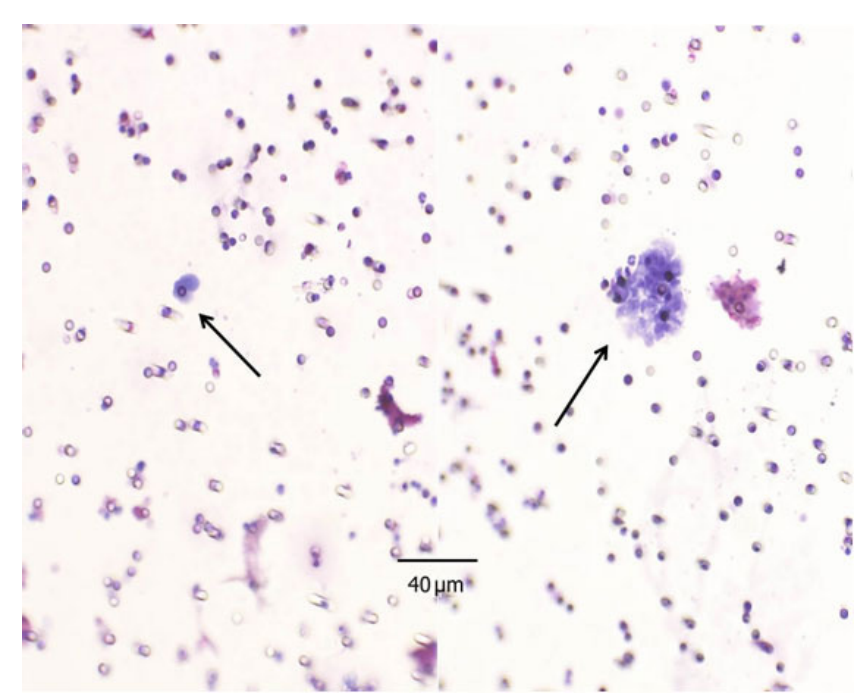

Figure 1: CTC detected around lung tumor biopsy. Left: singular CTC; right: cluster CTC. CTC: circulating tumor cell the peripheral circulating blood, as can occur with a surgical procedure. ${ }^{[12-15]}$

Initially, tumor cell dislodgement to the peripheral circulating blood by surgical manipulation was demonstrated using a cytological technique, but the sensitivity was very low. ${ }^{[17]}$ Later, polymerase chain reaction $^{[18,19]}$ and flow-cytometry ${ }^{[20]}$ methods were introduced to improve sensitivity and specificity, but results were not predictable. Morphological detection of CTC dislodgement was shown using the EpCAM positive selection method [CellSearch ${ }^{\circledR}$ system (Janssen Diagnostics, Raritan, NJ)], but the sensitivity was still low. ${ }^{[15]}$ As such, isolated tumor cells (ITC), surrogates of CTC, were extracted from pulmonary vein blood, revealing that detecting ITC/CTC was an indicator of early recurrence; the presence of cluster ITC/CTC indicated wrong prognosis, using the EpCAM positive selection method ${ }^{[21]}$ or the CD45 negativedepression gravity method [RosettSep ${ }^{\circledR}$ (Stemcell Technologies, Vancouver, Canada)]. ${ }^{[22-24]}$ As the sensitivity of such CTC detecting methods was not greater, the sample used pulmonary vein blood, because it contains more ITC/CTC than the peripheral circulating blood. ${ }^{[24]}$

Size selection methods [ISET ${ }^{\circledR}$ (Rarecells Diagnostics, Paris, France) and ScreenCell ${ }^{\circledR}$ Cyto] are highly sensitive for cluster CTC, and therefore the sampling of CTC extraction using size selection methods can use peripheral blood. ${ }^{[16,25]}$ Recently, CTC dislodgement during surgery for lung cancer was proven by detecting CTCs in the peripheral circulating blood using a size selection method, and the presence of cluster CTC has been an indicator of early recurrence among surgical lung cancer patients. ${ }^{[13]}$

A CTC assessment during FFB procedures needs a method that can extract CTCs from the peripheral blood sensitively, and for this reason we chose the sensitive

Table 1: Patient/tumor characteristics and status of CTC

\begin{tabular}{|c|c|c|c|c|c|c|c|c|c|c|c|c|c|c|}
\hline \multirow{3}{*}{ No. } & \multirow{3}{*}{ Age } & \multirow{3}{*}{ Gender } & \multicolumn{2}{|c|}{ CT findings } & \multirow{3}{*}{$\begin{array}{c}\text { Tumor } \\
\text { histology }\end{array}$} & \multicolumn{3}{|c|}{ Stage } & \multicolumn{6}{|c|}{ Status of CTC } \\
\hline & & & \multirow{2}{*}{ Type } & \multirow{2}{*}{$\begin{array}{l}\text { Size } \\
\text { (cm) }\end{array}$} & & \multirow{2}{*}{ C-stage } & \multirow[t]{2}{*}{ C-T } & \multirow[t]{2}{*}{$\mathrm{C}-\mathrm{N}$} & \multicolumn{2}{|c|}{$\begin{array}{c}\text { All CTC } \\
\text { categories }\end{array}$} & \multicolumn{2}{|c|}{$\begin{array}{c}\text { Singular } \\
\text { CTC }\end{array}$} & \multicolumn{2}{|c|}{ Cluster CTC } \\
\hline & & & & & & & & & Pre & Post & Pre & Post & Pre & Post \\
\hline 1 & 65 & $M$ & $\begin{array}{l}\text { Pure } \\
\text { solid }\end{array}$ & 2.1 & Invasive AD & IA & $1 \mathrm{~b}$ & 0 & 0 & 0 & 0 & 0 & 0 & 0 \\
\hline 2 & 64 & $M$ & Pure & 2.5 & Invasive AD & IA & $1 \mathrm{~b}$ & 0 & 0 & 2 & 0 & 2 & 0 & 0 \\
\hline 3 & 78 & M & $\begin{array}{l}\text { Pure } \\
\text { solid }\end{array}$ & 2.9 & Invasive AD & IA & $1 b$ & 0 & 0 & 0 & 0 & 0 & 0 & 0 \\
\hline 4 & 63 & $M$ & $\begin{array}{l}\text { Pure } \\
\text { solid }\end{array}$ & 2.4 & Invasive AD & IIIA & $1 b$ & 2 & 17 & 37 & 9 & 21 & 8 & 16 \\
\hline 5 & 59 & $F$ & $\begin{array}{l}\text { Pure } \\
\text { solid }\end{array}$ & 3.5 & Invasive AD & IB & $2 a$ & 0 & 0 & 0 & 0 & 0 & 0 & 0 \\
\hline 6 & 62 & M & $\begin{array}{l}\text { Pure } \\
\text { solid }\end{array}$ & 2.8 & Invasive AD & IA & $1 b$ & 0 & 0 & 5 & 0 & 5 & 0 & 0 \\
\hline
\end{tabular}

CT: computed tomography; CTC: circulating tumor cell; M: male; F: female; AD: adenocarcinoma; C: clinical; T: tumor; N: node 


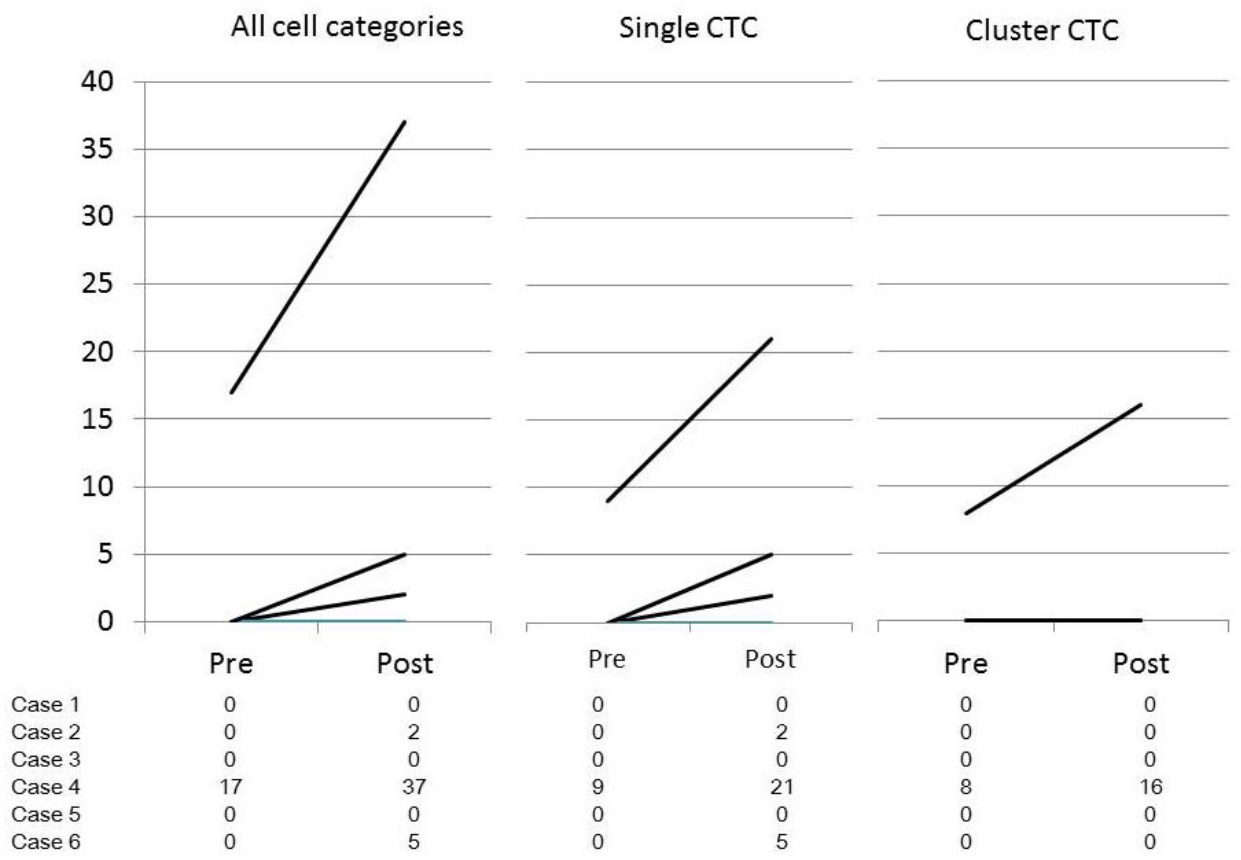

Figure 2: Alteration of circulating tumor cell count at pre- and at post-flexible fiber-topic bronchoscopy biopsy of lung cancer. CTC: circulating tumor cell

method of micropore membrane size selection. This let us that the FFB procedure causes CTCs dislodgement into the circulating blood, with distinguishing cluster CTC that may be a crucial indicator of tumorigenesis. ${ }^{[26]}$

In addition to tumor cell dissemination into the circulating blood by surgical manipulation and TBB, the pleural cavity and the surgical margin are other areas where cancer cells can be disseminated by interventions such as FNAC and pulmonary wedge resection. Sawabata et al. ${ }^{[2]}$ demonstrated cancer cell dissemination from a lung cancer lesion through the needle tract at the visceral pleura. This phenomenon may support the high rates of relapse as pleural carcinomatosis in surgical patients with lung cancer who undergo FNAC..$^{[3,4]}$ In cases of pulmonary wedge resection of lung cancer, malignant positive margin detected by cytology is an indicator of recurrence and poor survival, ${ }^{[6]}$ while attaining a malignant-negative margin of pulmonary wedge lung cancer resection is speculated to be an indicator of good prognosis. Altorki et al. ${ }^{[27]}$ reported a prognosis of pulmonary wedge lung cancer resection similar to that of segmentectomy when a wedge resection was carried out with sufficient margin distance and malignantnegative surgical margin.

In addition to surgical margin dissemination, residual lung lobe is another area where tumor cells are disseminated during pulmonary wedge lung cancer resection. ${ }^{[28]}$ The possibility of tumor cells in the residual lung lobe parenchyma is related to the margin distance from a cancer to the margin of the pulmonary wedge resection, and a detection of clustered tumor cells is an indicator of early recurrence. ${ }^{[28]}$ These observations in FNAC and surgery suggest that the importance of controlling cancer cell dissemination is as great in those settings as in TBB.

Although this study has the limitation of a relatively small patient population, results using the size selection method revealed an increased number of both singular and cluster CTC post-FFB biopsy, therefore, further investigation into the implications of such CTCs is recommended.

\section{Acknowledgments}

The authors thank Dr. Hiroshi Maruyama and Dr. Yuko Torii (Department of Pathology, Hoshigaoka Medical Center) for their contributions to the pathological diagnoses.

\section{Financial support and sponsorship}

This research was supported by a Grant-in-Aid for Scientific Research [(B) 25293301] from the Japan Ministry of Education, Science, Sports and Culture.

\section{Conflicts of interest}

There are no conflicts of interest.

\section{Patient consent}

All patients provided their informed consent to participate in this study. 


\section{Ethics approval}

This investigation was approved by the institutional review board of the Hoshigaoka Medical Center (No. 1412) in April 4, 2014.

\section{REFERENCES}

1. Sawabata N, Yokota S, Maeda H, Nakagawa M, Yamaguchi T, Okada T, Itho M. Diagnosis of solitary pulmonary nodule: optimal strategy based on nodal size. Interact Cardiovasc Thorac Surg 2006;5:105-8.

2. Sawabata N, Ohta M, Maeda H. Fine-needle aspiration cytologic technique for lung cancer has a high potential of malignant cell spread through the tract. Chest 2000;118:936-9.

3. Inoue $\mathrm{M}$, Honda $\mathrm{O}$, Tomiyama $\mathrm{N}$, Minami $\mathrm{M}$, Sawabata $\mathrm{N}$, Kadota Y, Shintani Y, Ohno Y, Okumura M. Risk of pleural recurrence after computed tomographic-guided percutaneous needle biopsy in stage I lung cancer patients. Ann Thorac Surg 2011;91:1066-71.

4. Kashiwabara K, Semba H, Fujii S, Tsumura S. Preoperative percutaneous transthoracic needle biopsy increased the risk of pleural recurrence in pathological stage I lung cancer patients with subpleural pure solid nodules. Cancer Invest 2016;34:373-7.

5. Robertson EG, Baxter G. Tumour seeding following percutaneous needle biopsy: the real story! Clinical radiol 2011;66:1007-14.

6. Sawabata N, Matsumura A, Ohota H, Maeda H, Hirano H, Nakagawa K, Matsuda H; Thoracic Surgery Study Group of Osaka University. Cytologically malignant margins of wedge resected stage I non-small cell lung cancer. Ann Thorac Surg 2002;74:1953-7.

7. Sawabata N, Karube Y, Umezu H, Tamura M, Seki N, Ishihama H, Honma K, Miyoshi S. Cytologically malignant margin without continuous pulmonary tumor lesion: cases of wedge resection, segmentectomy and lobectomy. Interact Cardiovasc Thorac Surg 2008;7:1044-8.

8. Sawabata N, Maeda H, Matsumura A, Ohta M, Okumura M; Thoracic Surgery Study Group of Osaka University. Clinical implications of the margin cytology findings and margin/tumor size ratio in patients who underwent pulmonary excision for peripheral non-small cell lung cancer. Surg Today 2012;42:238-44.

9. Takahashi N, Sawabata N, Kawamura M, Ohtsuka T, Horio H, Sakaguchi H, Nakayama M, Yoshiya K, Chida M, Hoshi E. Multicenter prospective study of sublobar resection for c-stage I non-small cell lung cancer patients unable to undergo lobectomy (KLSG-0801): complete republication. Gen Thorac Cardiovasc Surg 2016;64:470-5.

10. Sawabata N, Maeda H, Ohta M, Hayakawa M. Operable non-small cell lung cancer diagnosed by transpleural techniques: do they affect relapse and prognosis? Chest 2001;120:1595-8.

11. Nakajima J, Sato H, Takamoto S. Does preoperative transbronchial biopsy worsen the postsurgical prognosis of lung cancer? A propensity score-adjusted analysis. Chest 2005;128:3512-8.

12. Sawabata N, Okumura M, Utsumi T, Inoue M, Shiono H, Minami M, Nishida T, Sawa Y. Circulating tumor cells in peripheral blood caused by surgical manipulation of non-small-cell lung cancer: pilot study using an immunocytology method. Gen Thorac Cardiovasc Surg 2007;55:189-92.

13. Sawabata N, Funaki S, Hyakutake T, Shintani Y, Fujiwara A, Okumura M. Perioperative circulating tumor cells in surgical patients with nonsmall cell lung cancer: does surgical manipulation dislodge cancer cells thus allowing them to pass into the peripheral blood? Surg Today 2016;46:1402-9.

14. Hashimoto M, Tanaka F, Yoneda K, Takuwa T, Matsumoto S, Okumura Y, Kondo N, Tsubota N, Tsujimura T, Tabata C, Nakano T, Hasegawa $\mathrm{S}$. Significant increase in circulating tumour cells in pulmonary venous blood during surgical manipulation in patients with primary lung cancer. Interact Cardiovasc Thorac Surg 2014;18:775-83.

15. Yao X, Williamson C, Adalsteinsson VA, D'Agostino RS, Fitton T, Smaroff GG, William RT, Wittrup KD, Love JC. Tumor cells are dislodged into the pulmonary vein during lobectomy. $J$ Thorac Cardiovasc Surg 2014;148:3224-31.

16. Desitter I, Guerrouahen BS, Benali-Furet N, Wechsler J, Jänne PA, Kuang Y, Yanagita M, Wang L, Berkowitz JA, Distel RJ, Cayre YE. A new device for rapid isolation by size and characterization of rare circulating tumor cells. Anticancer Res 2011;31:427-41.

17. Hansen E, Wolff N, Knuechel R, Ruschoff J, Hofstaedter F, Taeger K. Tumor cells in blood shed from the surgical field. Arch Surg 1995; 130:387-93.

18. Yamashita J, Matsuo A, Kurusu Y, Saishoji T, Hayashi N, Ogawa M. Preoperative evidence of circulating tumor cells by means of reverse transcriptase-polymerase chain reaction for carcinoembryonic antigen messenger RNA is an independent predictor of survival in non-small cell lung cancer: a prospective study. J Thorac Cardiovasc Surg 2002;124:299-305.

19. Brown DC, Purushotham AD, Birnie GD, George WD. Detection of intraoperative tumor cell dissemination in patients with breast cancer by use of reverse transcription and polymerase chain reaction. Surgery 1995; 117:95-101.

20. Allard WJ, Matera J, Miller MC, Repollet M, Connelly MC, Rao C, Tibbe AG, Uhr JW, Terstappen LW. Tumor cells circulate in the peripheral blood of all major carcinomas but not in healthy subjects or patients with nonmalignant diseases. Clin Cancer Res 2004; 10:6897-904.

21. Crosbie PA, Shah R, Krysiak P, Zhou C, Morris K, Tugwood J, Booton $\mathrm{R}$, Blackhall F, Dive C. Circulating tumor cells detected in the tumordraining pulmonary vein are associated with disease recurrence after surgical resection of NSCLC. J Thorac Oncol 2016;11:1793-7.

22. Funaki S, Sawabata N, Nakagiri T, Shintani Y, Inoue M, Kadota Y, Minami M, Okumura M. Novel approach for detection of isolated tumor cells in pulmonary vein using negative selection method: morphological classification and clinical implications. Eur $J$ Cardiothorac Surg 2011;40:322-7.

23. Funaki S, Sawabata N, Abulaiti A, Shintani Y, Inoue M, Kadota Y, Minami M, Okumura M. Significance of tumour vessel invasion in determining the morphology of isolated tumour cells in the pulmonary vein in non-small-cell lung cancer. Eur J Cardiothorac Surg 2013;43:1126-30.

24. Okumura Y, Tanaka F, Yoneda K, Hashimoto M, Takuwa T, Kondo $\mathrm{N}$, Hasegawa S. Circulating tumor cell in pulmonary venous blood of primary lung cancer patients. Ann Thorac Surg 2009;87:1669-75.

25. Ma YC, Wang L, Yu FL. Recent advances and prospects in the isolation by size of epithelial tumor cells (ISET) methodology. Technol Cancer Res Treat 2013;12:295-309.

26. Aceto N, Bardia A, Miyamoto DT, Donaldson MC, Wittner BS, Spencer JA, Yu M, Pely A, Engstrom A, Zhu H, Brannigan BW, Kapur R, Stott SL, Shioda T, Ramaswamy S, Ting DT, Lin CP, Toner M, Haber DA, Maheswaran S. Circulating tumor cell clusters are oligoclonal precursors of breast cancer metastasis. Cell 2014;158:1110-22.

27. Altorki NK, Kamel MK, Narula N, Ghaly G, Nasar A, Rahouma M, Lee PC, Port JL, Stiles BM. Anatomical segmentectomy and wedge resections are associated with comparable outcomes for patients with small cT1N0 non-small cell lung cancer. $J$ Thorac Oncol 2016;11:1984-92.

28. Sawabata N, Funaki S, Shintani Y, Okumura M. Lung excision of nonsmall-cell lung cancer leaves cancer cells in residual lobe: cytological detection using pulmonary vein blood. Interact Cardiovasc Thorac Surg 2016;22:131-5. 